\title{
Changes in the Activation Energy of Radiation Defects in Strongly Defected Silicon Depending on the Type and Concentration of Dopant
}

\author{
P. WęGieREK* AND P. BilleWiCZ \\ Lublin University of Technology, Nadbystrzycka 38A, 20-618 Lublin, Poland
}

\begin{abstract}
The article presents the outcome of the research on alternating-current electric conduction in silicon doped with boron, phosphorus, and antimony of resistivities $\rho=0.01 \Omega \mathrm{cm}$ and $\rho=10 \Omega \mathrm{cm}$, strongly defected by the implantation of $\mathrm{Ne}^{+}$ions $\left(D=1.5 \times 10^{14} \mathrm{~cm}^{-2}, E=100 \mathrm{keV}\right)$. On the basis of results obtained for samples annealed at the temperature $T_{\mathrm{a}}=598 \mathrm{~K}$ and measured at the testing temperature $T_{\mathrm{p}}=298 \mathrm{~K}$ and frequency $f=1 \mathrm{MHz}$ it was possible to carry out an analysis of mechanisms of electric conduction depending on the type and concentration of dopant. Obtained results confirmed the occurrence of hopping conductivity mechanism in strongly defected semiconductors, which is typical for high frequency values.
\end{abstract}

DOI: $10.12693 /$ APhysPolA.125.1392

PACS: 61.72.uj, 61.72.Cc, 72.80.Ey

\section{Introduction}

In order to confirm the model of hopping conductivity proposed in the papers [1-3] as well as to analyze mechanisms of electric conduction in strongly defected semiconductors which were described in [4] it is necessary to determine influence of the testing frequency and annealing temperature on measured parameters like conductivity and permeability (capacity) and to estimate values of the conduction activation energy and dipoles relaxation time.

The analysis presented in this article is fundamentally based on the phenomenon which had been discovered in the nineties of the twentieth century. The essence of this phenomenon, which has been described in the work [5], was the anomalous increase in the dielectric permittivity of silicon irradiated with high fluence of neutrons. In the subsequent years it was necessary to conduct a research which included examination of the silicon strongly defected by ion implantation as well as semiconductor compounds $\mathrm{A}^{2} \mathrm{~B}^{6}$ with transition metals. In both cases the same phenomenon of thermally activated dielectric growth had been observed, as described in [6-8].

The research has been carried out on $p$-type silicon doped with boron characterized by two different resistivity values: $\rho=0.01 \Omega \mathrm{cm}$ and $\rho=10 \Omega \mathrm{cm}$ as well as $n$-type silicon doped with phosphorus of resistivity $\rho=10 \Omega \mathrm{cm}$ and antimony of resistivity $\rho=0.01 \Omega \mathrm{cm}$, implanted with $\mathrm{Ne}^{+}$ions of the $E=100 \mathrm{keV}$ energy and a fluence of $D=1.5 \times 10^{14} \mathrm{~cm}^{-2}$. Implantations have been made at room temperature, using the implanter with the ion source described in [9-13].

*corresponding author; e-mail: p.wegierek@pollub.pl
Results of experimental measurements of conductivity and capacity registered in the alternating-current circuit within the frequency ranging from $50 \mathrm{~Hz}$ to $5 \mathrm{MHz}$ have been analyzed. Experiment covered testing temperatures from $77 \mathrm{~K}$ to $373 \mathrm{~K}$ and the samples have been isochronously annealed for $15 \mathrm{~min}$, within the $T_{\mathrm{a}}$ temperature range up to $873 \mathrm{~K}$, with an average increase rate of $30 \div 50 \mathrm{~K}$. The experimental part of the work, including preparation of the samples, has been carried out in accordance with the methodology described in detail in the paper [14].

\section{Analysis of the obtained results}

In Fig. 1a and b dependences $\sigma=\mathrm{f}(f)$ and $C_{p}=\mathrm{f}(f)$, recorded at the temperature $T_{\mathrm{p}}=298 \mathrm{~K}$ for samples isochronously annealed in the temperature $T_{\mathrm{a}}=598 \mathrm{~K}$ are presented, respectively. Considering the relative position of the curves $\sigma=\mathrm{f}(f)$ and $C_{p}=\mathrm{f}(f)$, it is possible to observe that presented plots are nearly the same, despite the fact that each sample is characterized by different type of doping and values of resistivity of the particular samples differ from each other by three orders of magnitude. Such situation confirms occurrence of the jump mechanism of electric charge transfer between particular defects. As it is known, total conductivity could be expressed as a superposition of the two components, band one and the jump one [15]. Analysis of the dependences shown in Fig. 1a and b leads to the conclusion that in described case total conductivity is strongly dominated by jump component. Otherwise, sample conductivity should be inversely proportional to its resistivity, which would cause relative curves displacement.

The alternative way of the analysis of electric conduction mechanisms in silicon strongly defected by ion implantation has been aimed at determination of the annealing temperature influence ratio in relation to con- 

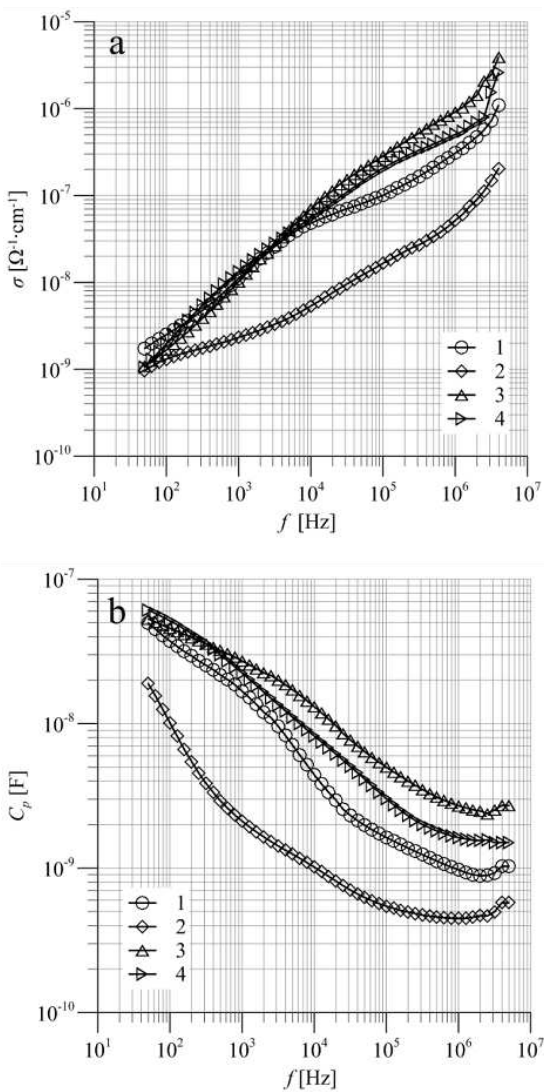

Fig. 1. Dependences $\sigma=\mathrm{f}(f)$ (a) and $C_{p}=\mathrm{f}(f)$ (b) for samples of $\mathrm{Ne}^{+}$implanted silicon with ion fluence $D=1.5 \times 10^{14} \mathrm{~cm}^{-2}$ and energy $E=100 \mathrm{keV}$, annealed at $T_{\mathrm{a}}=598 \mathrm{~K}$, measured at $T_{\mathrm{p}}=298 \mathrm{~K}$. Samples parameters: $1-\mathrm{Si}+\mathrm{B}$ ( $p$-type), $\rho=10 \Omega \mathrm{cm}$, $2-\mathrm{Si}+\mathrm{P}(n$-type), $\rho=10 \Omega \mathrm{cm}, 3-\mathrm{Si}+\mathrm{B}(p$-type $)$, $\rho=0.01 \Omega \mathrm{cm}, 4-\mathrm{Si}+\mathrm{Sb}(n$-type $), \rho=0.01 \Omega \mathrm{cm}$.

ductivity (Fig. 2a) and capacity (Fig. 2b) of the tested samples.

By analyzing presented dependences it is possible to distinguish temperature ranges that correspond to certain processes. For $T_{\mathrm{a}}<423 \mathrm{~K}$ only insignificant conductivity swings have been observed, which means that charge carrier compensation rate in the allowed energy band is constant and results from a relevant value of radiation defect concentration. For the testing temperatures ranging from $423 \mathrm{~K}$ to $523 \mathrm{~K}$ conductivity and capacity gently decrease and then it is possible to observe increase in its values $\left(523 \mathrm{~K}<T_{\mathrm{a}}<653 \mathrm{~K}\right)$ and finally significant decrease $\left(T_{\mathrm{a}}>653 \mathrm{~K}\right)$. Initial phase of the described process is probably due to annealing of some of the radiation defects, e.g. Si-P3 and Si-P6. The second phase of this phenomenon results from increased value of resultant concentration of deep radiation defects (e.g. Si-P1 and Si-B3), that are so-called trapping centers for charge carriers. Consequently, electron quantity decreases simultaneously causing reduction in the conductivity. Additionally, for the temperatures above $623 \mathrm{~K}$
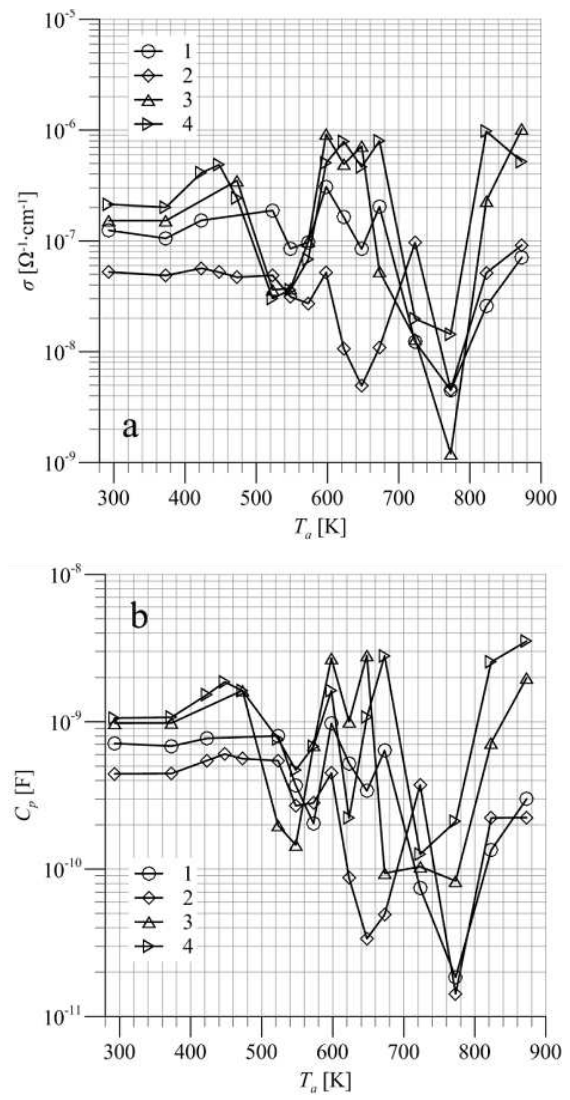

Fig. 2. Dependences $\sigma=\mathrm{f}\left(T_{\mathrm{a}}\right)$ (a) and $C_{p}=\mathrm{f}\left(T_{\mathrm{a}}\right)$ (b) for samples of $\mathrm{Ne}^{+}$implanted silicon with ion fluence $D=1.5 \times 10^{14} \mathrm{~cm}^{-2}$ and energy $E=100 \mathrm{keV}$, measured at $T_{\mathrm{p}}=298 \mathrm{~K}$ and $f=1 \mathrm{MHz}$. Samples parameters: $1-\mathrm{Si}+\mathrm{B}(p$-type $), \rho=10 \Omega \mathrm{cm}, 2-\mathrm{Si}+\mathrm{P}(n$-type $)$, $\rho=10 \Omega \mathrm{cm} ; 3-\mathrm{Si}+\mathrm{B}$ (p-type), $\rho=0.01 \Omega \mathrm{cm}$, $4-\mathrm{Si}+\mathrm{Sb}(n$-type), $\rho=0.01 \Omega \mathrm{cm}$.

plots $\sigma=\mathrm{f}\left(T_{\mathrm{a}}\right)$ and $C_{p}=\mathrm{f}\left(T_{\mathrm{a}}\right)$ could be influenced by annealing of radiation defects which have occurred at lower temperatures and also by the decrease in concentration of such types of radiation defects like Si-P1 and Si-B3 that gradually decay as the annealing temperature rises [16].

Dependences of conductivity $\sigma$ and capacity $C_{p}$ on the temperature for testing frequency $f=1 \mathrm{MHz}$ have been presented respectively in Fig. 3a and b. They make a basis for estimating the value of conduction activation energy $\Delta E$, which could be used for identification of radiation defects and evaluation of their energies. Therefore it was necessary to perform a fit of selected parts of characteristics $\sigma=\mathrm{f}\left(1000 / T_{\mathrm{p}}\right)$ and $C_{p}=\mathrm{f}\left(1000 / T_{\mathrm{p}}\right)$ with the function $\ln (y)=A x+B$. Then, the values of $\Delta E$ have been calculated according to the formula $\Delta E=A 1000 k$.

Jump activation energies estimated on the basis of the dependence $\sigma=\mathrm{f}\left(1000 / T_{\mathrm{p}}\right)$ and $C_{p}=\mathrm{f}\left(1000 / T_{\mathrm{p}}\right)$ for the individual samples reveal a high degree of alignment (see Table), which means that jumps of electrons run from one neutral defect to the other neutral defect and cause increase of the conductivity. Dipoles created as 

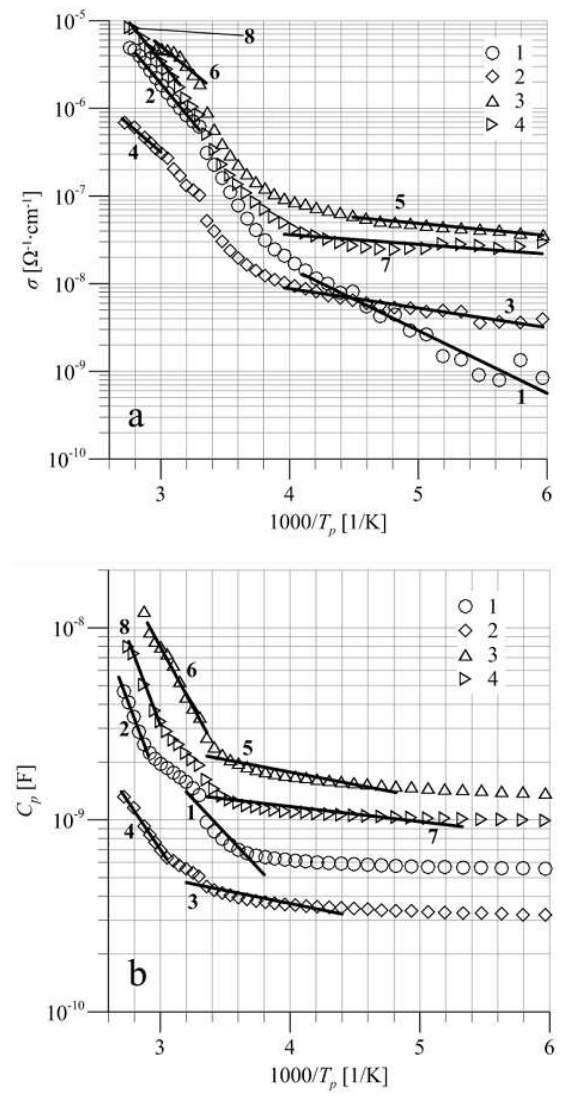

Fig. 3. Dependences $\sigma=\mathrm{f}\left(1000 / T_{\mathrm{p}}\right)$ (a) and $C_{p}=$ $\mathrm{f}\left(1000 / T_{\mathrm{p}}\right)$ (b) for samples of $\mathrm{Ne}^{+}$implanted silicon with ion fluence $D=1.5 \times 10^{14} \mathrm{~cm}^{-2}$ and energy $E=100 \mathrm{keV}$, annealed at $T_{\mathrm{a}}=598 \mathrm{~K}$, measured at $f=1 \mathrm{MHz}$. Samples parameters: $1-\mathrm{Si}+\mathrm{B}$ ( $p$-type), $\rho=10 \Omega \mathrm{cm}, 2-\mathrm{Si}+\mathrm{P}$ ( $n$-type) $\rho=10 \Omega \mathrm{cm}, 3-$ $\mathrm{Si}+\mathrm{B}(p$-type $), \rho=0.01 \Omega \mathrm{cm}, 4-\mathrm{Si}+\mathrm{Sb}(n$-type), $\rho=0.01 \Omega \mathrm{cm}$.

the consequence of mentioned jumps contribute to the increase in the values of the capacity of tested samples. In all cases the activation energies have been calculated on the basis of the fits prepared for two ranges of the testing temperatures including respectively $167 \div 253 \mathrm{~K}$ and $303 \div 363 \mathrm{~K}$. High values of activation energy $\Delta E=$ $0.24 \div 0.36 \mathrm{eV}$, calculated on the basis of capacity and conductivity mean that jump conduction runs over the potential barrier of the radiation defects. Those values also indicate the position of neutral defect energy bands with respect to the bottom of the conduction band.

Figure 4 presents values of the frequency coefficient $\alpha$, calculated according to the formula $\sigma \sim f^{\alpha}$ as the function of testing frequency $f$, which has been estimated on the basis of the dependence $\sigma=\mathrm{f}(f)$ from Fig. 1b. Location and relative width of the areas of the local maxima occurring in the mentioned plots are connected with different types of radiation defects which appeared in the tested material. Those defects are characterized by similar values of the activation energy, however differ from each other by the values of the lifetime of the dipoles

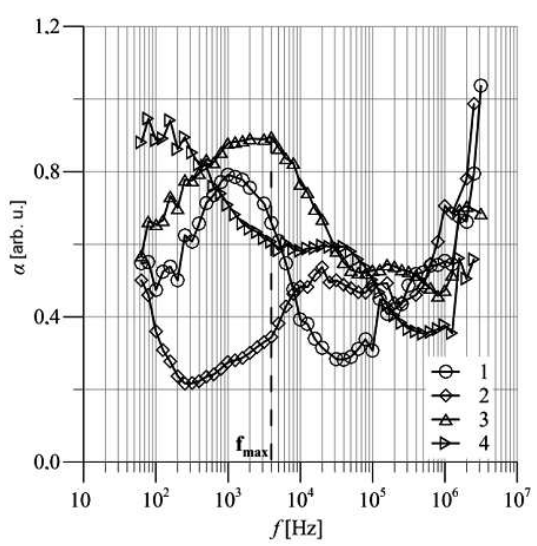

Fig. 4. Dependences $\alpha=\mathrm{f}(f)$ for samples of $\mathrm{Ne}^{+}$implanted silicon with ion fluence $D=1.5 \times 10^{14} \mathrm{~cm}^{-2}$ and energy $E=100 \mathrm{keV}$, annealed at $T_{\mathrm{a}}=598 \mathrm{~K}$, measured at $f=1 \mathrm{MHz}$. Samples parameters: $1-\mathrm{Si}+\mathrm{B}$ $(p$-type $), \rho=10 \Omega \mathrm{cm}, 2-\mathrm{Si}+\mathrm{P}(n$-type $), \rho=10 \Omega \mathrm{cm}$, $3-\mathrm{Si}+\mathrm{B}$ ( $p$-type), $\rho=0.01 \Omega \mathrm{cm}, 4-\mathrm{Si}+\mathrm{Sb}(n$-type), $\rho=0.01 \Omega \mathrm{cm}$.

TABLE

Activation energy values for the testing frequency $f=$ $1 \mathrm{MHz}$. Samples parameters: $1-\mathrm{Si}+\mathrm{B}$ (p-type), $\rho=$ $10 \Omega \mathrm{cm}, 2-\mathrm{Si}+\mathrm{P}$ ( $n$-type) $\rho=10 \Omega \mathrm{cm}, 3-$ $\mathrm{Si}+\mathrm{B}(p$-type $), \rho=0.01 \Omega \mathrm{cm}, 4-\mathrm{Si}+\mathrm{Sb}(n$-type $)$, $\rho=0.01 \Omega \mathrm{cm}$

\begin{tabular}{|c|c|c|c|c|c|}
\hline $\begin{array}{c}\text { Number } \\
\text { of } \\
\text { sample }\end{array}$ & $\begin{array}{c}\text { Approxi- } \\
\text {-mation } \\
\text { range }\end{array}$ & $\begin{array}{l}\text { Measured } \\
\text { parameter }\end{array}$ & $\begin{array}{c}\text { Activation } \\
\text { energy } \\
{[\mathrm{eV}]}\end{array}$ & $\begin{array}{l}\text { Measured } \\
\text { parameter }\end{array}$ & $\begin{array}{c}\text { Activation } \\
\text { energy } \\
{[\mathrm{eV}]}\end{array}$ \\
\hline \multirow{2}{*}{1} & 1 & \multirow{8}{*}{$\sigma$} & 0.14 & \multirow{8}{*}{$C_{p}$} & 0.14 \\
\hline & 2 & & 0.35 & & 0.36 \\
\hline \multirow{2}{*}{2} & 3 & & 0.04 & & 0.03 \\
\hline & 4 & & 0.25 & & 0.20 \\
\hline \multirow{2}{*}{3} & 5 & & 0.03 & & 0.03 \\
\hline & 6 & & 0.24 & & 0.25 \\
\hline \multirow{2}{*}{4} & 7 & & 0.02 & & 0.02 \\
\hline & 8 & & 0.36 & & 0.36 \\
\hline
\end{tabular}

$\tau$ [17], which have been calculated according to the formula $\tau \approx 1 / \omega=1 /\left(2 \pi f_{\max }\right)$ and presented in Fig. 5 .

The dependence $\tau=\mathrm{f}\left(1000 / T_{\mathrm{p}}\right)$ has been fitted with the function $\ln (y)=A x+B$ in the same way as in the case of calculating the values of activation energies on the basis of conductivity and capacity dependences of inverted temperature $T_{\mathrm{p}}$. Activation energies calculated for the particular samples considering the dependence $\tau=\mathrm{f}\left(1000 / T_{\mathrm{p}}\right)$ equal respectively: $\Delta E_{1}=0.84 \mathrm{eV}$, $\Delta E_{2}=0.35 \mathrm{eV}, \Delta E_{3}=0.48 \mathrm{eV}$, and $\Delta E_{4}=0.35 \mathrm{eV}$. The values of activation energies calculated above determine the band energy of radiation defects staying in the negative charge state. It is necessary to emphasize that activation energy estimated for samples 2 and 4 (silicon of resistivity $\rho=0.01 \Omega \mathrm{cm}$ ) equals $0.35 \mathrm{eV}$, whereas for the material of resistivity $\rho=10 \Omega \mathrm{cm}$ it reaches the level of $0.48 \mathrm{eV}$ and $0.84 \mathrm{eV}$. Such situation confirms that in the samples with greater resistivity higher potential barrier has appeared. 


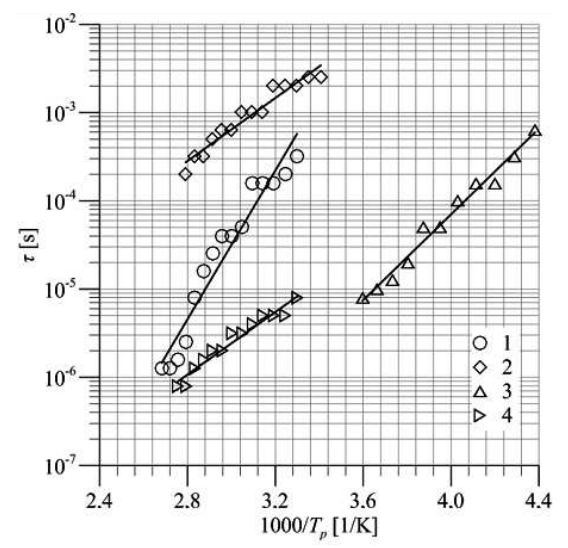

Fig. 5. Dependences $\tau=\mathrm{f}\left(1000 / T_{\mathrm{p}}\right)$ for samples of $\mathrm{Ne}^{+}$implanted silicon with ion fluence $D=1.5 \times$ $10^{14} \mathrm{~cm}^{-2}$ and energy $E=100 \mathrm{keV}$, annealed at $T_{\mathrm{a}}=$ $598 \mathrm{~K}$, measured at $f=1 \mathrm{MHz}$. Samples parameters: $1-\mathrm{Si}+\mathrm{B}$ ( $p$-type), $\rho=10 \Omega \mathrm{cm}, 2-\mathrm{Si}+\mathrm{P}(n$-type), $\rho=10 \Omega \mathrm{cm}, 3-\mathrm{Si}+\mathrm{B}$ ( $p$-type), $\rho=0.01 \Omega \mathrm{cm}$, $4-\mathrm{Si}+\mathrm{Sb}(n$-type), $\rho=0.01 \Omega \mathrm{cm}$.

\section{Conclusions}

The article presents the results of research on $p$-type silicon doped with boron as well as the $n$-type one doped with phosphorus and antimony, strongly defected by implantation of neon ions of the fluence $1.5 \times 10^{14} \mathrm{~cm}^{-2}$. These results have been analyzed from the viewpoint of various mechanisms of electric conduction.

It has been observed that the type and the concentration of dopant have very little impact on the conductivity and the capacity of tested samples, which confirms the theory that mechanism of hopping electric charge transfer is a dominating mechanism of electric conductivity for high frequency values. At the same time it has been verified that there is a strong dependence between measured electrical parameters and annealing temperature $T_{\mathrm{a}}$, which proves that the value of $T_{\mathrm{a}}$ is directly related with changes in concentration of different types of radiation defects, which are typical for specified values of the annealing temperature.

It has been established that two types of radiation defects are responsible for the increase of conductivity and capacity values within the testing temperature range $168 \div 363 \mathrm{~K}$. For those defects it has been possible to determine the band energies. For the testing temperatures from the considered range values of relaxation times (which mean the time while electric charge stays in the neutral potential well after making a jump) have also been calculated.

The obtained experimental results and conclusions are in accordance with those presented in the articles [18, 19], concerning electric conduction mechanisms in silicon of different electric parameters.

\section{References}

[1] P. Zukowski, T. Koltunowicz, J. Partyka, P. Wegierek, F.F. Komarov, A.M. Mironov, N. Butkievith, D. Freik, Vacuum 81, 1137 (2007).

[2] T.N. Koltunowicz, P. Zhukowski, V.V. Fedotova, A.M. Saad, A.K. Fedotov, Acta Phys. Pol. A 120 , 39 (2011).

[3] P. Żukowski, T. Kołtunowicz, J. Partyka, Yu.A. Fedotova, A.V. Larkin, Vacuum 83, S280 (2009).

[4] P. Zukowski, P. Węgierek, P. Billewicz, T.N. Koltunowicz, F. Komarov, Acta Phys. Pol. A 120, 125 (2011).

[5] P.W. Zukowski, S.B. Kantorow, K. Kiszczak, D. Maczka, A. Rodzik, V.F. Stelmakh, E. CzarneckaSuch, Phys. Status Solidi A-Appl. Res. 128, K117 (1991).

[6] P.W. Zukowski, A. Rodzik, Yu.A. Shostak, Semiconductors 31, 610 (1997).

[7] P.V. Zukowski, J. Partyka, P. Węgierek, J.W. Sidorenko, J.A. Szostak, A. Rodzik, Semiconductors 33, 276 (1999).

[8] P. Zukowski, J. Partyka, P. Wegierek, Yu. Shostak, Yu. Sidorenko, A. Rodzik, Semiconductors 34, 1124 (2000).

[9] M. Turek, A. Droździel, K. Pyszniak, D. Mączka, Przeglad Elektrotechniczny 11b, 328 (2012) (in Polish).

[10] M. Turek, A. Drozdziel, K. Pyszniak, S. Prucnal, D. Mączka, Y.V. Yushkevich, Y.A. Vaganov, Instrum. Exp. Tech. 55, 469 (2012).

[11] M. Turek, S. Prucnal, A. Drozdziel, K. Pyszniak, Rev. Sci. Instrum. 80, 043304 (2009).

[12] M. Turek, S. Prucnal, A. Drozdziel, K. Pyszniak, Nucl. Instrum. Methods Phys. Res. B 269, 700 (2011).

[13] J. Żuk, M. Turek, K. Pyszniak, A. Droździel, S. Prucnal, Przeglad Elektrotechniczny 7, 193 (2010) (in Polish).

[14] P. Węgierek, Electric Conductance in Strongly Defected Semiconductors Modified with Ion Techniques, Monography, Politechnika Lubelska, Lublin 2013 (in Polish).

[15] P. Węgierek, M. Kowalski, Electronics - Constructions, Technologies, Appliances 9, 100 (2009) (in Polish).

[16] R.C. Newman, D.N.J. Totterdell, J. Phys. C, Solid State Phys. 8, 3944 (1975).

[17] N.F. Mott, E.A. Davis, Electronic Process in Noncrystalline Materials, Clarendon Press, Oxford 1979.

[18] P. Węgierek, P. Billewicz, Acta Phys. Pol. A 120, 122 (2011).

[19] P. Węgierek, P. Billewicz, Acta Phys. Pol. A 123. 948 (2013). 